\title{
Prediction of the Infiltration from Thickened Tailings to the Natural Ground
}

\author{
J. Moreno SRK Consulting Chile S.A., Chile \\ M. Palape SRK Consulting Chile S.A., Chile
}

\begin{abstract}
The issue of infiltration from tailings dams is one of the most critical to address in the permitting process. Thickened tailings and paste tailings should have clear advantages given the reduced pore water content relative to conventional tailings and the generally lower permeability owing to the non-segregation; nevertheless doubts remain as to how much of this water will seep into the ground and how deep it will travel. This was evaluated by undertaking a bench scale trial coupled with mathematical modelling for the feasibility design of a new copper operation.
\end{abstract}

The bench scale thickener plant was run at the project site within the Atacama Desert; it comprised of a $0.9 \mathrm{~m}$ diameter thickener to produce a designed slurry density of $67 \%$ solids (by wt) and a pump to convey the tailings to a single central discharge site which allowed the tailings to spread directly on top of natural alluvial deposits to form a tailings cone.

The scope of the investigation included a special testing programme tailored to predict the infiltration rate from the tailings cone and the depth to which the underlying soil would be impacted. The programme comprised periodic sampling of the deposited tailings and soils, during and after the disposal operation. Laboratory tests determined the variations in moisture content, gravimetric properties, and the saturated and unsaturated characteristics of both tailings and underlying alluvial materials.

This particular investigation aimed to predict infiltration into the ground surface from a thickened tailings disposal operation considering unsaturated conditions. The software VS2Dti from the United States Geological Survey (USGS) was chosen to model the tailings and underlying soil and incorporated the in situ conditions such as moisture content of the soil and evaporation rate to calibrate the model. Several model runs were conducted for variable thicknesses of fresh tailings with evaporative periods of approximately 30 days between each disposal event. Predicted moisture content of the tailings and soils for each successive tailings layer was plotted and was compared to the in situ conditions after the disposal trials.

The results of the investigations indicated a low potential for infiltration such that the depth to which the underlying soils would be impacted upon would be limited. Evaporation from the surface of the tailings would reduce saturation within the tailings body to less than $80 \%$ while the underlying soils would remain unsaturated. The depth to which the underlying soils are affected depends on the thickness of the initial deposited tailings layer, to a maximum of $2 \mathrm{~m}$ depth of impact and the soil characteristics. After that, the addition of further layers of fresh tailings has no further or very limited impact.

\section{Introduction}

Infiltration from tailings to natural soil occurs at variable rates and depends on particular characteristics of the tailings, basin cover, site climatology and other more subtle factors. It is a fact that all tailings leak to some extent and the appropriate question is at what rate and how far seepage water will go.

Thickened tailings, paste and filtered tailings are deposited at very low water contents (Vick, 1983), therefore, it is thought that infiltration would be reduced compared to conventional tailings. However, there is very limited experience on how the infiltration can be quantified with some degree of accuracy, since very little water or no water might be reclaimed from these deposits. While it is initially a design problem during the operational period of a mine, it is ultimately a closure and post-closure issue, and the evaluation of water quality and quantity through time is an important aspect of reclamation planning (Caldwell et al., 1984). 
Tailings in general, experience several changes after deposition into a basin, all related to the amount of water contained in the pores (interstitial water). These changes occur over time through various steps: plug sedimentation, self-weight consolidation, desiccation and unsaturation (Oliveira-Filho and van Zyl, $2006 \mathrm{a}, \mathrm{b}$ ) and can take several years and even extend to post-closure.

The thickened tailings technique accelerates the first step, as plug sedimentation is promoted in the thickener by adding flocculants thus reducing the interstitial water prior to depositing it in the basin.

In dry environments, where little rain and a high evaporation rate prevails, the loss of the bulk of the water occurs by evaporation and by initial infiltration as the tailings spread over the basin, leaving tailings at the desiccation phase in a few days.

This paper analyses the fate of the interstitial water just before desiccation has started considering that selfweight consolidation is not complete.

\section{General}

Before disposal, thickened tailings are treated with flocculants and allowed to settle to a design solid content. Solid particles gather together to form larger particles and therefore sediment faster and easier. When high solids content tailings are disposed over a dry surface, interstitial water has three potential pathways, exit the surface as evaporation, infiltrate into the surface below or remain inside the tailings pores, as shown in Figure 1.

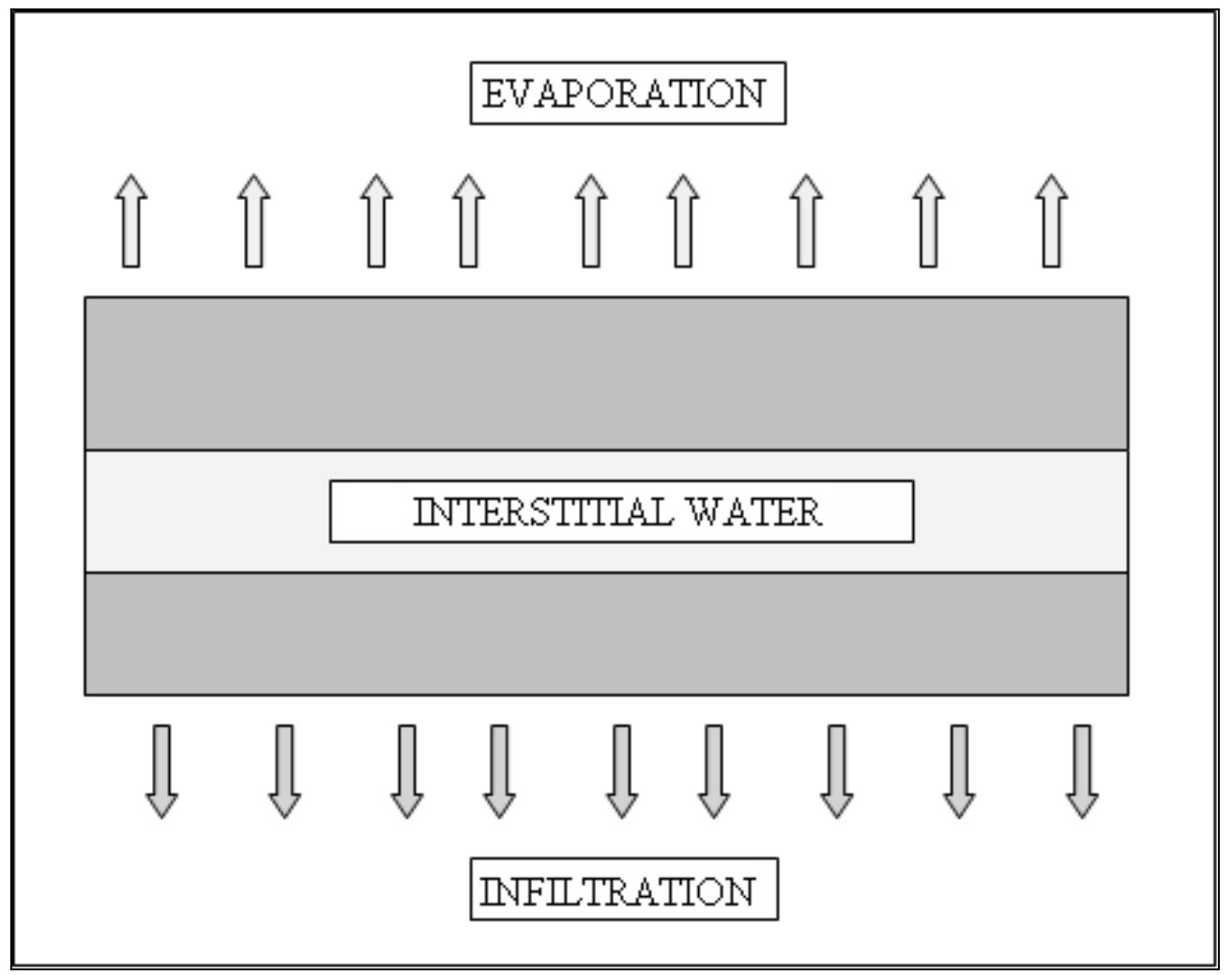

\section{Figure 1 Water balance scheme of the tailings mass}

As excess water is released from the tailings, it starts to de-saturate when its moisture content reaches the shrinkage limit. This process takes several months, even years for conventional tailings; however with thickened tailings disposed in a very dry environment it could happen in days, even hours after deposition. Figure 2 shows cracking of fresh disposed thickened tailings that started in less than two days at the Atacama Desert, northern Chile. 


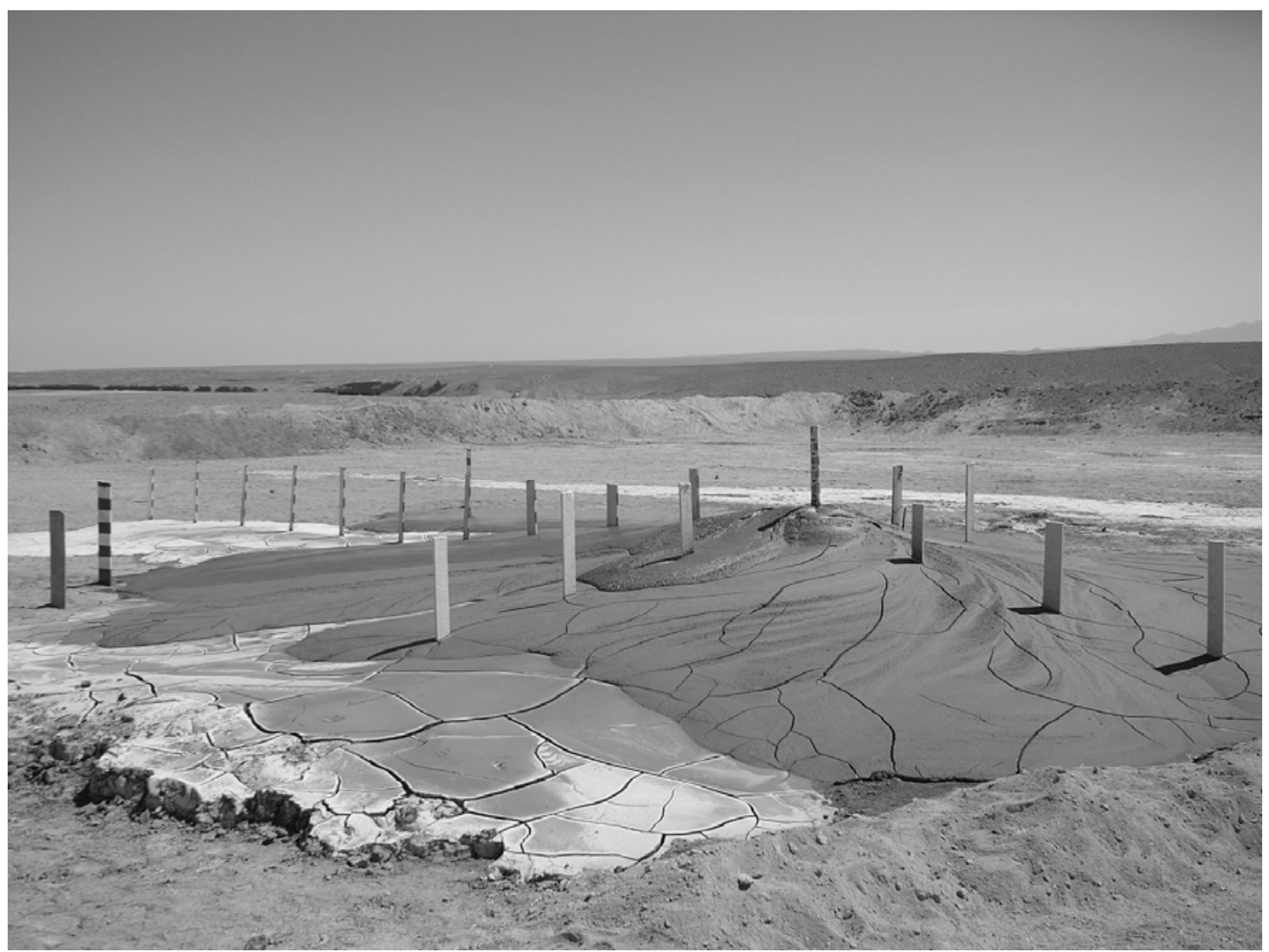

Figure 2 Thickened tailings showing early cracking

Infiltration from tailings occurs immediately as the tailings spread from the distribution system over the basin. Excess water segregates from the solids and evaporates out or infiltrates into the soil. Normally, with silt-like tailings, the consolidation process occurs relatively quickly; thus the pore volume can be considered constant after primary self-weight consolidation has been achieved.

For short-term conditions, the amount of interstitial water in a given tailings lift is a transient variable that would reach a steady state at some point, considering that the stress conditions remain constant for that period.

In general, the water balance for a new lift of tailings is a complex process that involves several unknown variables (Rykaart, 2001) but can be simplified considering just three main components:

$$
\mathrm{Q}=\mathrm{Q}_{\mathrm{E}}+\mathrm{Q}_{\mathrm{I}}+\mathrm{Q}_{\mathrm{R}}
$$

Where:

$\mathrm{Q}=$ water introduced into the tailings deposit.

$\mathrm{Q}_{\mathrm{E}}=$ evaporation flow rate from the tailings deposit.

$\mathrm{Q}_{\mathrm{I}}=$ infiltration flow rate.

$\mathrm{Q}_{\mathrm{R}}=$ interstitial water.

In order to incorporate the unsaturated flow regime issues into this investigation, a numerical model based on the software VS2DTi (USGS) was used. The inputs were taken from a field investigation set out in two phases, one in Santiago and the other at a site in the Atacama Desert. The tailings stream for both cases came from the same mill and process therefore grain size and chemical composition of the mixture were the same. 


\section{Field investigation}

A pilot process plant was set up in Santiago, Chile using ore from an exploration gallery. As part of the metallurgical plan, a bench scale thickener was added to the process, which facilitated the production of fresh tailings. The Chilean Centre for Mining and Metallurgy (CIMM) laboratory in Santiago provided an open space to install a distribution pipe and spread the tailings over a concrete slab, simulating a single discharge operation. Several tailings cones were produced and samples retrieved from the cone and tested for moisture content. Additionally, tailings were stored in boxes to obtain moisture content with time.

The Santiago pilot plant investigated a range of tailings solids (55 to $72 \%$ ), while the site test evaluated the thickened tailings at $67 \%$ only.

There were doubts about whether these tests would accurately simulate the site conditions, because the climate in Santiago is different from that in the Atacama Desert, and the bottom drainage in the CIMM pilot test was restricted by a concrete slab. Therefore, a second campaign was planned at the proposed site, where a thickener and pump were installed and dried tailings from the Santiago campaign were shipped to the test site in bags.

The cone tests at the site were similar to those in Santiago, and consisted of a bench scale tailings disposal site. It comprised a $0.9 \mathrm{~m}$ diameter thickener to produce a design slurry density of $67 \%$ solids (by wt) and a pump to convey the tailings to a single central discharge which allowed the tailings to spread directly on top of natural alluvium deposits to form a tailings cone. The cone was divided into four quadrants, and samples were retrieved from the tailings periodically to obtain the moisture content curve of each sample. Test pits were dug at the rim of the cone and samples were taken from 0.5 to $1 \mathrm{~m}$ depth for moisture content tests before, during and after the cone trials, as shown in Figure 3.

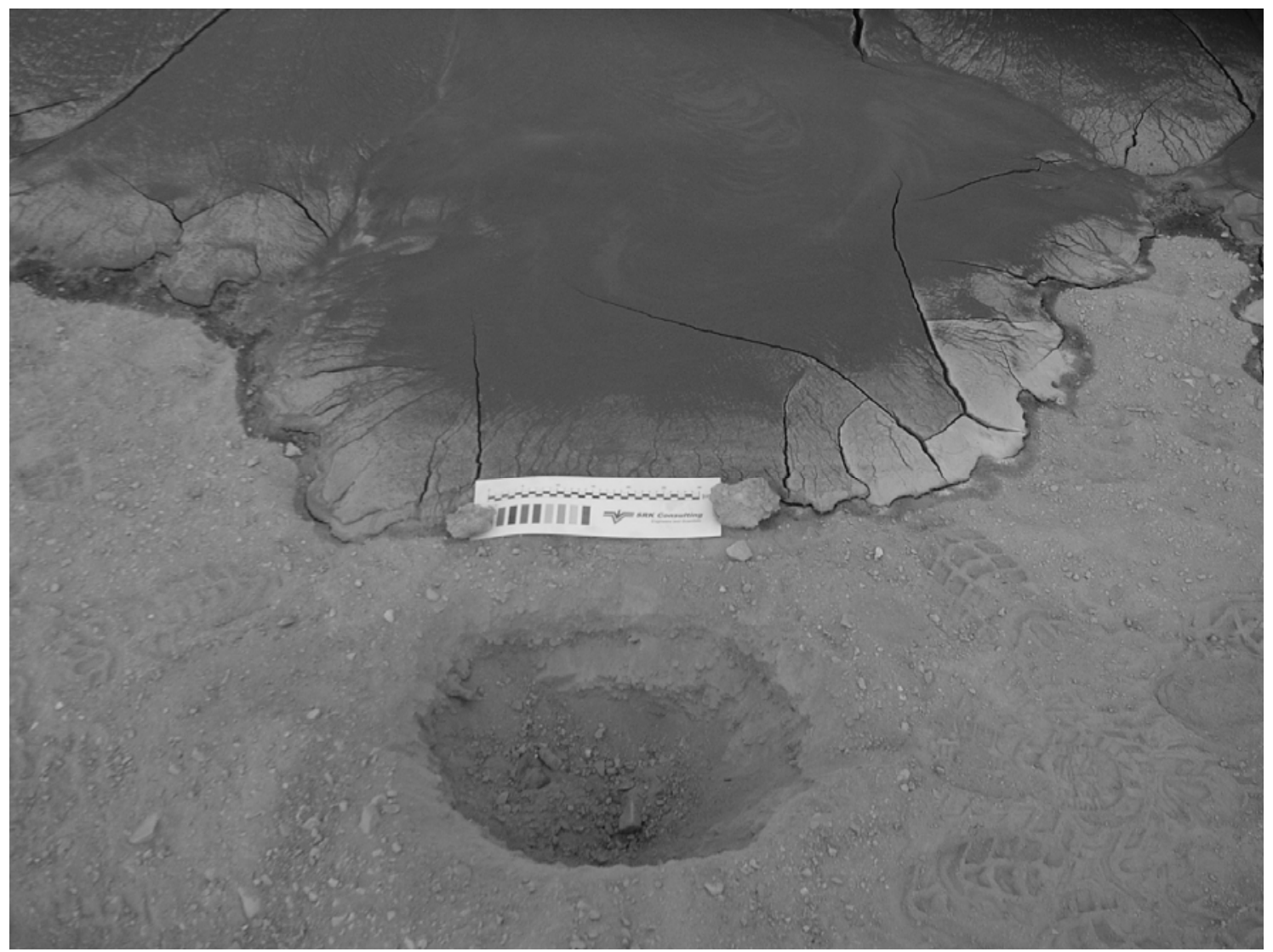

\section{Figure 3 Test pit to retrieve foundation samples}

Freshly deposited tailings were stored in air-tight containers and alluvial samples representative of the foundation were obtained from the test pits. These samples were shipped to Daniel B. Stephens and 
Associates' laboratory in Albuquerque to perform a standard hydraulic package test, including the soil water characteristic curve (SWCC).

A rapid loss of moisture was observed during the deposition phase, in part because of the high solids concentration but mostly because of the dry environment, i.e. cracks formed two days after deposition. Figure 4 shows the variation of moisture content for both the Santiago and site plants. It can be seen that regardless of the test location, a rapid loss of water is experienced with the tailings. It should be noted that some of the moisture results from Santiago even fell beneath those from the test site.

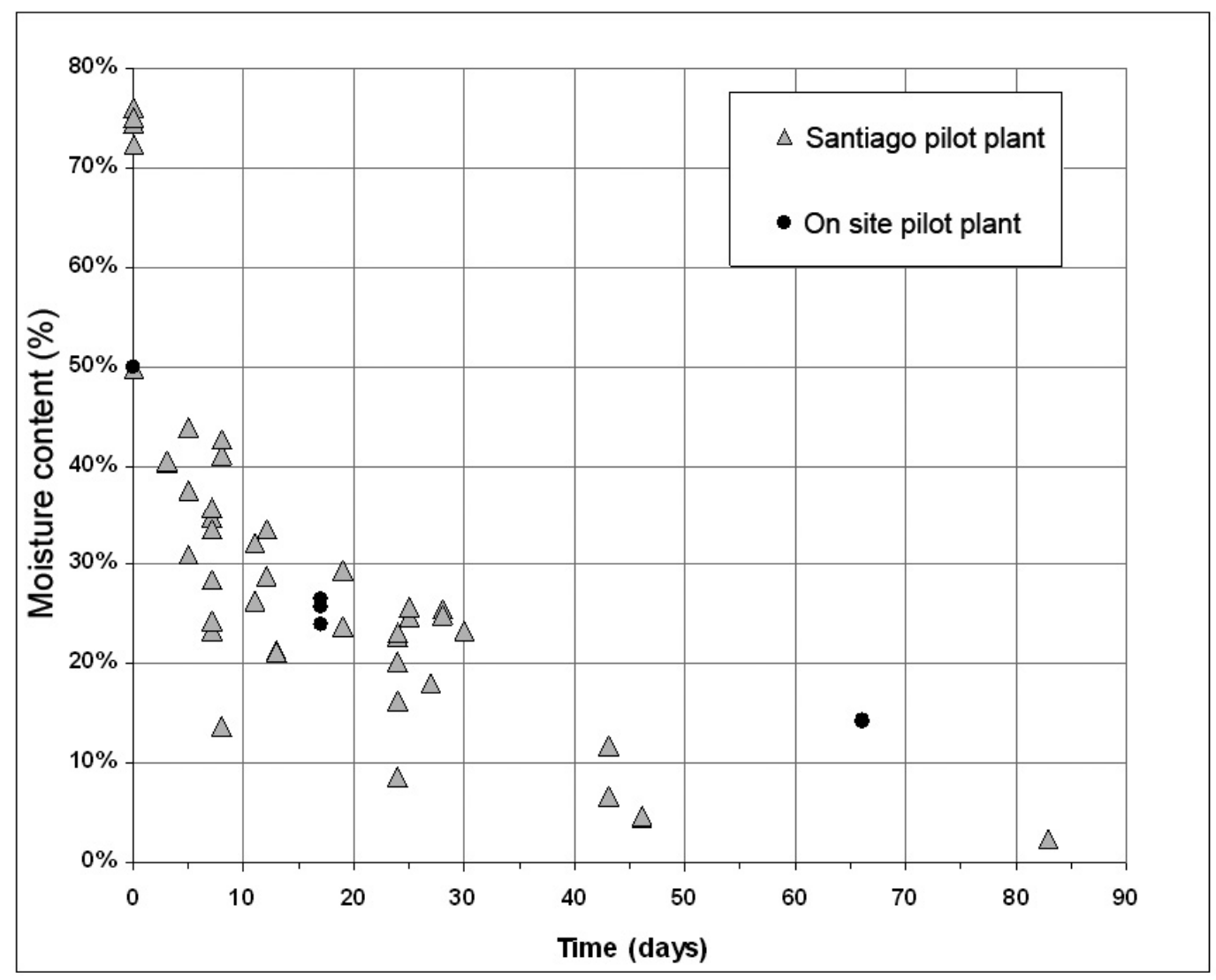

\section{Figure 4 Moisture content variation with time of the tailings}

During tailings deposition, test pits at various locations were excavated for sampling and observation. After nine days of deposition, it was found that infiltration from the tailings mass was not significant. The samples showed that the moisture content varied from $1 \%$ to a maximum of $11 \%$, averaging at $6 \%$ for normal operative conditions at $1 \mathrm{~m}$ of depth. Figure 5 shows how the moisture content varied with time during deposition in the test pits identified as downstream and upstream of the cone. It must be noted that during Day 2, the plant had to release tailings at a density of less than $50 \%$ solids and free water ran beyond the tailings rim, infiltrating directly into the alluvium. This is consistent with the sudden rise and subsequent drop of the moisture content of the alluvium after Day 2. 


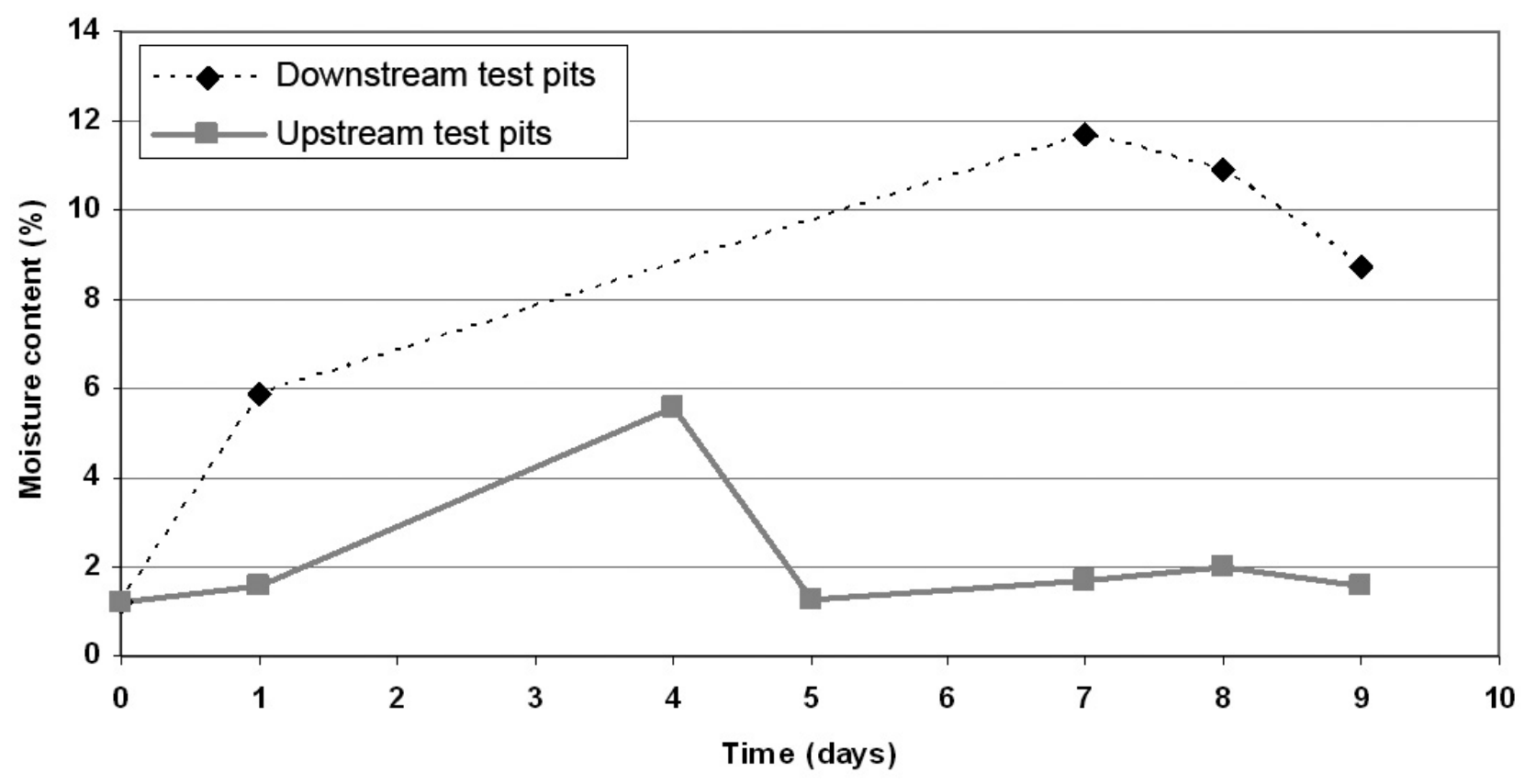

Figure 5 Variation of moisture content of the alluvium with time

\section{$4 \quad$ Numerical model}

The approach used for the modelling of infiltration from conventional tailings, especially in dry environments, cannot be used for thickened tailings, because it does not have a steady recharge boundary, i.e. pond and/or unconsolidated slurry that are normally the water sources for the model. For thickened tailings, the source of water is limited and the tailings passes to an unsaturated state very rapidly.

Figure 4 showed that water loss from the tailings decreased dramatically within days after deposition mainly due to evaporation and therefore it is assumed that most of the water transfer from the tailings to the soil occurs when the tailings are close to its shrinkage limit, which is more into the unsaturated threshold. Traditional analysis of unsaturated flow assumes no volume changes, and then volumetric water content can be used to describe water volume changes (Oliveira-Filho and van Zyl, 2006a). The constitutive relationship used to describe the unsaturated flow analysis is known as the soil-water characteristic curve (SWCC), where the parameters are dependent on the degree of saturation and matric suction.

There are various software packages capable of handling unsaturated flow using the SWCC, one of which is VS2DTi developed by the USGS. In general, it can easily model complex variables such as evaporation, unsaturated flow considering variable moisture content and matric suction among others.

VS2DTi is a graphical software package for simulating flow and transport in variably saturated porous media in one or two dimensions using cartesian or radial coordinate systems. The numerical models used for flow and transport calculations are the U.S. Geological Survey's computer models VS2DT (Hsieh et al., 2000). VS2DT is a finite-difference model that solves Richard's equation for fluid flow, and the advectiondispersion equation for solute transport. Relations between pressure head, moisture content, and relative hydraulic conductivity may be represented by functions developed by van Genuchten (1980), Brooks and Corey (1964), Haverkamp et al. (1977), or by data points. Initial hydraulic conditions that can be specified include static equilibrium, specified pressure head, or specified moisture content. Boundary conditions include specified pressure or total head, specified flux, infiltration with ponding, evaporation, plant transpiration, and seepage faces.

The geotechnical and hydraulic parameters used as input to the model were obtained from the laboratory and are shown in Table 1. 
Table 1 Input parameters for the VS2DTi model

\begin{tabular}{lcc}
\hline Property & Tailings & Alluvium \\
\hline Specific gravity of solids $\left(\mathrm{gr} / \mathrm{cm}^{3}\right)$ & 2.65 & 2.65 \\
Saturation density $\left(\mathrm{gr} / \mathrm{cm}^{3}\right)$ & 1.94 & 2.05 \\
Dry density $\left(\mathrm{gr} / \mathrm{cm}^{3}\right)$ & 1.51 & 1.68 \\
Porosity $(\%)$ & 43.0 & 36.6 \\
Saturated hydraulic conductivity $(\mathrm{cm} / \mathrm{s})$ & $5.1 \mathrm{E}-06$ & $1.0 \mathrm{E}-04$ \\
Van Genuchten parameters (unsaturated flow) & & \\
$\alpha\left(\mathrm{cm}^{-1}\right)$ & 0.0046 & 0.0213 \\
$\beta($ dimensionless) & 1.2832 & 1.8701 \\
Residual moisture content $\theta_{\mathrm{r}}(\% \mathrm{vol})$ & 3.70 & 5.77 \\
Saturated moisture conteṇt $\theta_{\mathrm{s}}(\% \mathrm{vol})$ & 44.02 & 30.20 \\
\hline
\end{tabular}

The model assumes an initial moisture content smaller than or equal to the porosity and conversely greater than or equal to the residual moisture content at any point of the domain.

In this particular case, the residual moisture content for the alluvium was found to be $5.77 \%$. However, natural moisture content tests from the field indicated a value of $1.2 \%$. This is consistent for a soil from a very dry environment without precipitation for long periods.

In order to cater for this difference, the residual moisture content $\left(\theta_{\mathrm{r}}\right)$ of $0.5 \%$ was used as an input parameter which made an adjustment to the van Genuchten curve necessary. The van Genuchten parameters ( $\alpha$ and $\beta)$ were calibrated to meet the in situ conditions using the mean-squares technique. The modified parameters are shown in Table 2.

Table 2 Van Genuchten adjusted parameters

\begin{tabular}{lcc}
\hline Van Genuchten Parameters - Alluvium & Tested & Modified \\
\hline$\alpha\left[\mathrm{cm}^{-1}\right]$ & 0.0213 & 0.0263 \\
$\beta$ [dimensionless] & 1.8701 & 1.4763 \\
Residual moisture content $\theta_{\mathrm{r}}[\% \mathrm{vol}]$ & 5.77 & 0.50 \\
Saturated moisture conteṇt $\theta_{\mathrm{s}}[\mathrm{vol}]$ & 30.20 & 30.20 \\
\hline
\end{tabular}

Figure 6 shows the adjustment made to take into account the discrepancy between the laboratory and site conditions. It was assumed that the pressure head associated with lower moisture contents than those found in the laboratory will not exceed the matric suction obtained in the laboratory because dewatering of natural soils in the desert occurred over a long period of time. 


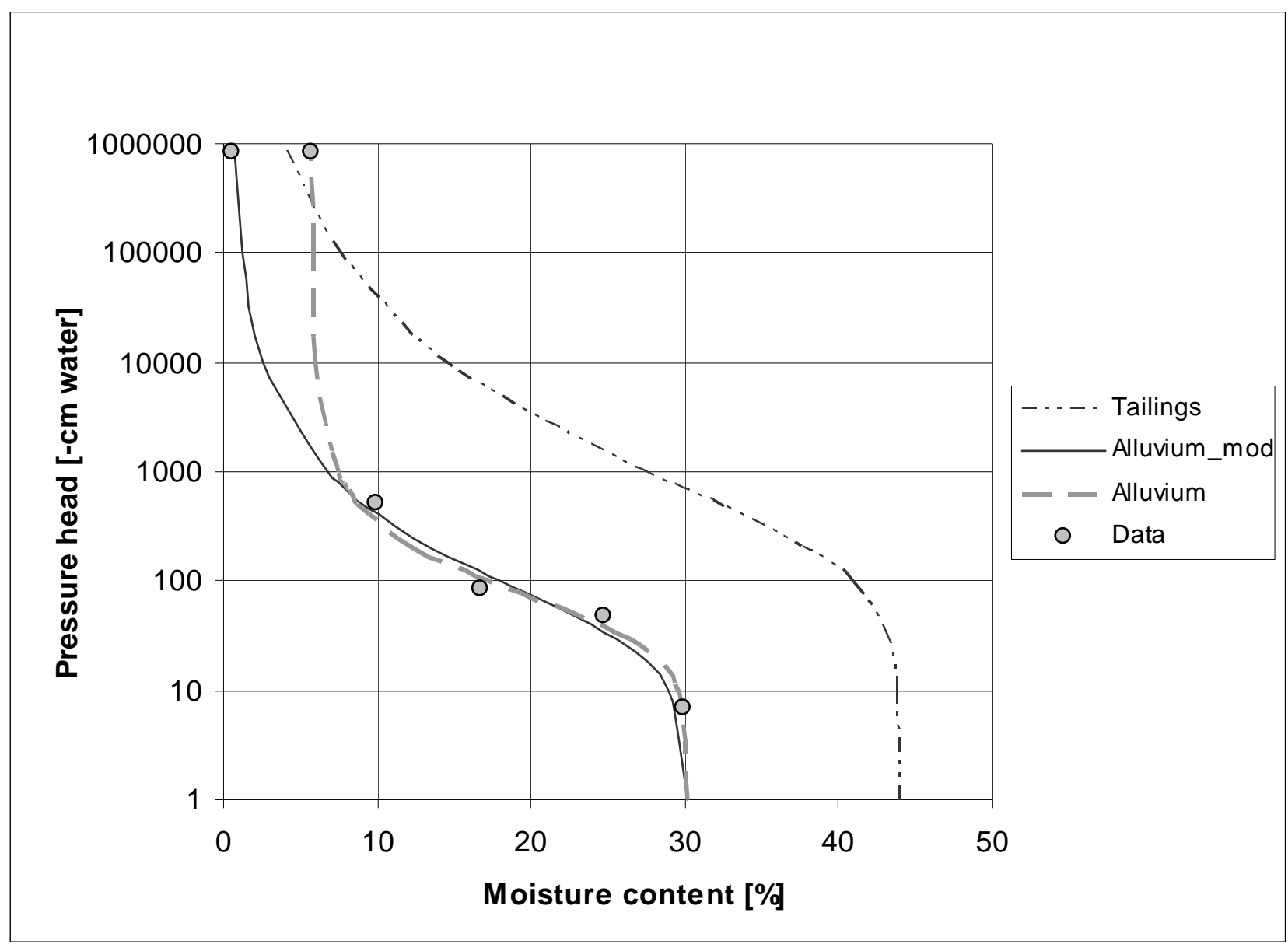

Figure 6 Soil-water characteristic curve - adjusted

VS2DTi was used to calculate the exchange of moisture between the tailings, atmosphere and alluvium, passing from a saturated state to an unsaturated regime. Moisture content can be expressed as the quantity of water compared to solids weight (gravimetric) or as the volume of water in terms of the total volume (volumetric). The software uses the volumetric approach. However geotechnical engineers prefer gravimetric moisture in order to display results. In order to facilitate the reading of the results, gravimetric units were used. However if volumetric moisture content is used, it will be clearly highlighted.

The tailings initial gravimetric moisture content $\left(\omega_{i n i}\right)$ was estimated using the following expression:

$$
\omega_{i n i}=\left(\frac{1-c_{p}}{c_{p}}\right)
$$

In this expression, $c_{p}$ represents the solids content of the thickener underflow. For this project, a minimum $c_{p}$ $=67 \%$ was estimated. From (2), $\omega_{i n i}=50 \%$ is obtained or in volumetric terms, VMC $=75 \%$.

From Table 1, the porosity of the tailings (n) is $43 \%$. The difference between porosity and initial VMC of the tailings is $32 \%$, meaning that there is excess water in the tailings which must be considered in the analysis. In order to take this difference into account, a pond was simulated on top of the fresh tailings layer. The initial height of ponding was calculated as $32 \%$ of the thickness of the deposited layer and was considered as a free evaporative-infiltration boundary.

Evaporation occurs through variable conditions throughout the day, and can differ between day and night mainly due to temperature differences. The cycles to model day and night evaporation were considered in the model. 
The basic input parameters for the evaporation process are:

- Potential evaporation during the day: $8 \mathrm{~mm} /$ day $=9.26 \times 10^{-8} \mathrm{~m} / \mathrm{s}$.

- Potential evaporation during the night: $3 \mathrm{~mm} /$ day $=3.47 \times 10^{-8} \mathrm{~m} / \mathrm{s}$.

- Pressure potential of atmosphere (HA) may be computed using the Kelvin equation:

$$
H A=\frac{R \cdot T \cdot \ln \left(h_{a}\right)}{M_{w} \cdot g}
$$

Where $R \quad=$ Universal gas constant $=8.32 \mathrm{~J} / \mathrm{mol}^{\circ} \mathrm{K}$.

$T=$ Temperature in degrees Kelvin $=293^{\circ} \mathrm{K}$ (day) and $278^{\circ} \mathrm{K}$ (night).

$h_{a} \quad=$ Relative humidity of atmosphere $=20 \%$.

$M_{w} \quad=$ Molecular weight of water $=0.018 \mathrm{~kg} / \mathrm{mol}$.

$g \quad=$ acceleration due to gravity $=9.8 \mathrm{~m} / \mathrm{s}^{2}$.

The atmospheric pressure for evaporation was then calculated from (3):

$$
\begin{aligned}
\mathrm{HA}_{\text {day }} & =-22219 \mathrm{~m} \\
\mathrm{HA}_{\text {night }} & =-21081 \mathrm{~m}
\end{aligned}
$$

The cycles are defined as periods of 12 hours each. Evaporation parameters are defined at the beginning of each period (day and night), and are assumed to vary linearly.

The model was set to evaluate the tailings VMC 30 days after deposition has commenced. The output results were used as initial conditions for subsequent layers. The thickness of each tailings layer was fixed at $0.2 \mathrm{~m}$. Every newly deposited layer was run for a further 30 days and so on.

The domain of the problem was set as a 1D column, $1 \mathrm{~m}$ wide and $5 \mathrm{~m}$ deep. The foundation soil was modelled as a dry alluvium with a $\mathrm{VMC}=1.7 \%$. The tailings had an initial $\mathrm{VMC}$ of $43 \%$. The thickness of the fresh tailings was set at $0.2 \mathrm{~m}$ with initial water ponding of $0.06 \mathrm{~m}$. The model was run to represent tailings drying/seeping for 30 days having the water balance calculated at irregular intervals, depending on the convergence of the calculations. This analysis was repeated in five stages, piling a fresh $0.2 \mathrm{~m}$ of tailings on top during every stage of 30 days, completing a total of $1 \mathrm{~m}$ of tailings.

\section{$5 \quad$ Results of infiltration model}

The model for the first layer was run for 30 days, during which the moisture content was monitored continuously. The moisture content of the tailings varied from 29 to $15 \%$ as shown in Table 3 .

Table 3 Initial conditions and results after first run

\begin{tabular}{lcccccc}
\hline & \multicolumn{3}{c}{ Initial Conditions } & \multicolumn{3}{c}{ End of Run } \\
\hline Layer & Depth & Time & Moisture & Depth & Time & Moisture \\
\cline { 2 - 7 } & $\mathrm{m}$ & days & {$[\% \mathrm{wt}$. $]$} & $\mathrm{m}$ & days & {$[\% \mathrm{wt}]$.} \\
\hline 1st tailings layer & 0.20 to 0.00 & 0 & $29 \%$ & 0.20 to 0.00 & 30 & $15 \%$ \\
\hline Infiltrated alluvium & 0.00 to -0.25 & 0 & $1 \%$ & 0.00 to -0.25 & 30 & $4 \%$ \\
\hline Dry alluvium & 0.00 to -5.00 & 0 & $1 \%$ & -0.25 to -5.00 & 30 & $1 \%$ \\
\hline
\end{tabular}


There is a gap between the tailings layer and the alluvium where the moisture changes abruptly from 15 to $4 \%$. This is due to the inability of the dry alluvium to accommodate water from the tailings with a low pressure gradient available, which is consistent with the SWCC.

The output of this initial run was used as the initial conditions for a subsequent layer of tailings. It was run for a further 30 days and moisture content variation was computed within the problem domain. The procedure was repeated until the tailings layer reached a thickness of $1 \mathrm{~m}$.

It was observed that the tailings consistently dried down to a moisture content of $18 \%$ while the alluvium increased its moisture content from 1 up to $4 \%$.

The underlying soil affected by the infiltration in general increased in depth as fresh tailings layers were deposited on top. Nevertheless, it was found that below a depth of $1 \mathrm{~m}$ the variation in moisture content was negligible.

Figure 7 shows the moisture content distribution of the tailings and alluvium versus time considering various tailings layers up to a total layer thickness of $1 \mathrm{~m}$.

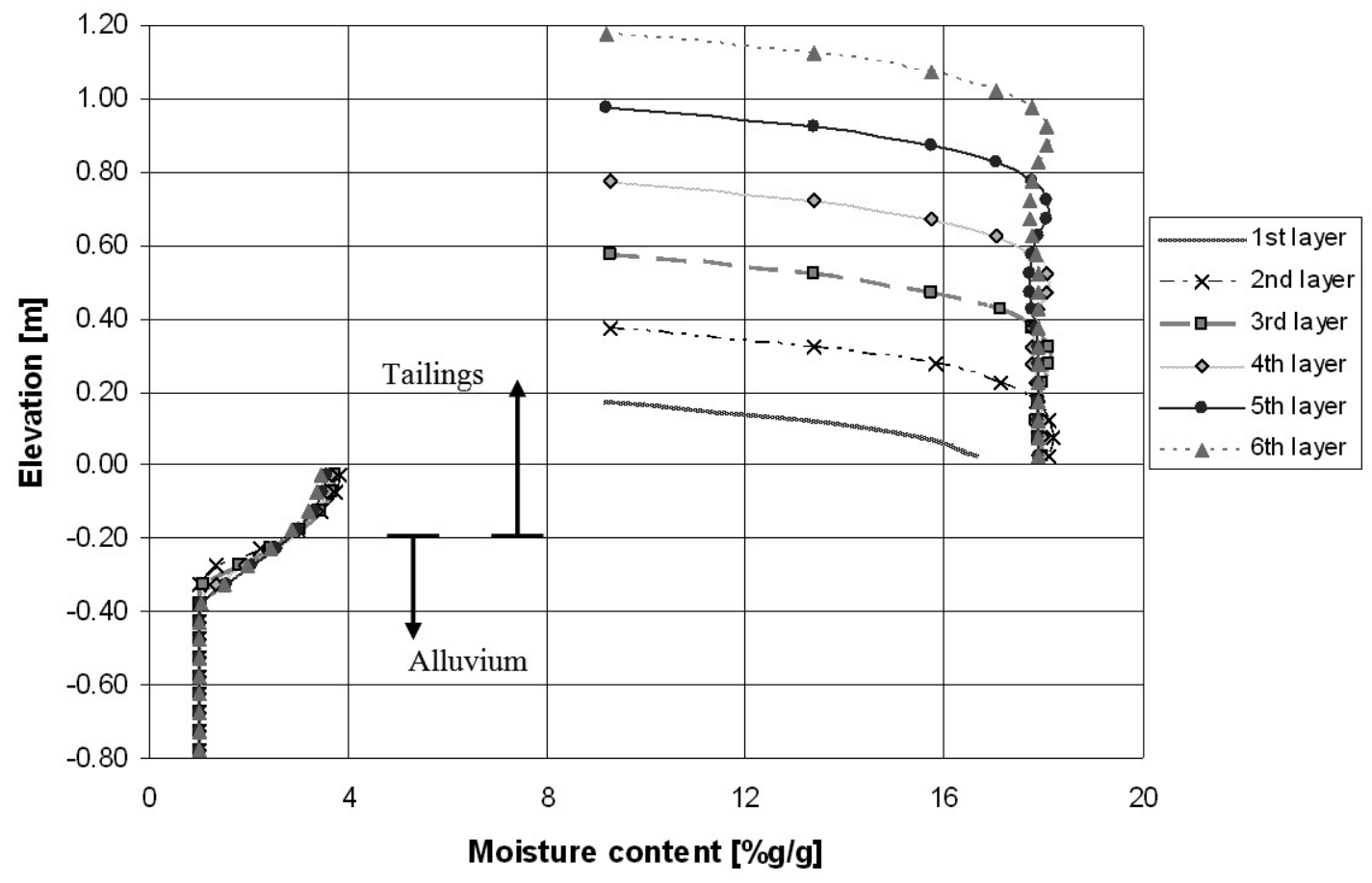

Figure 7 Variation of the moisture content of tailings and alluvium after 30 days

\section{Conclusions}

The results of the computer modelling correlated well with the site results, which showed that the tailings remained unsaturated, when deposited in relatively thin layers. The results also showed that infiltration mainly occurs within the uppermost $1 \mathrm{~m}$ of alluvium, while the moisture content of the soils below that increased negligibly. In addition, the moisture content of the underlying soils remains significantly below the saturation level, i.e. no seepage.

The testing and modelling also showed that there would be no water available for recovery, either from the tailing surface or the sub-surface. However, it should be noted that during operational conditions, there may be run-off from rain or during low density events. Rainfall was not taken into account as it occurs as infrequent events, but it could be modelled as transient ponding water. However it is envisaged that small variations will be obtained as the tailings crust is fairly impervious after completion of the drying cycle. 


\section{References}

Brooks, R.H. and Corey, A.T. (1964) Hydraulic properties of porous media: Hydrology Papers, Colorado State University, $24 \mathrm{p}$.

Caldwell, J.A., Fergusson, K., Schiffman, R.L. and van Zyl, D. (1984) Application of finite strain consolidation theory for engineering design and environmental planning of mine tailings impoundments. Yong, R.N. and Townsend, F.C. (eds). Proc. of the ASCE Symposium on Sedimentation and Consolidation Models, San Francisco, pp. 581606.

Haverkamp, R., Vaclin, M., Touma, J., Wierenga, P.J. and Vachaud, G. (1977) A comparison of numerical simulation models for one-dimensional infiltration, Soil Sci. Soc. Am. J. 41, pp. 285-294.

Hsieh, P.A., Wingle, W., Richard, W. and Healy, R.W. (2000) VS2DI-A Graphical Software Package for Simulating Fluid Flow and Solute or Energy Transport in Variably Saturated Porous Media, U.S. Geological Survey.

Oliveira-Filho, W.L. and van Zyl, D. (2006a) Modeling discharge of interstitial water from tailings following deposition. Part 1: Phenomenology and model description. Solos e Rochas, Sao Paulo, pp. 199-209.

Oliveira-Filho, W.L. and van Zyl, D. (2006b) Modeling discharge of interstitial water from tailings following deposition. Part 2: Application. Solos e Rochas, Sao Paulo, pp. 211-221.

Rykaart, E.M. (2002) A Methodology to Describe Spatial Surface Flux Boundary for Solving Tailings Impoundment Closure Water Balance Problems. PhD Thesis, University of Saskatchewan, Saskatoon, Canada.

van Genuchten, M.T. (1980) A closed form equation for predicting the hydraulic conductivity of unsaturated soils. Soil Science Society America Journal, pp. 890-892.

Vick, S.G. (1983) Planning, Design, and Analysis of Tailings Dams. John Wiley \& Sons, New York, New York. 